\title{
A study of the acute and chronic changes in ventilatory capacity of workers in Lancashire cotton mills
}

\author{
G. BERRY, C. B. MCKERROW, ${ }^{1}$ M. K. B. MOLYNEUX, ${ }^{2 *}$ \\ C. E. ROSSITER, ${ }^{1}$ and J. B. L. TOMBLESON ${ }^{3}$ \\ Medical Research Council's Pneumoconiosis Unit, Penarth, Glamorgan, ${ }^{1}$ Department of \\ Occupational Health, University of Manchester, ${ }^{2}$ and H.M. Medical Inspectorate of Factories ${ }^{3}$
}

\begin{abstract}
Berry, G., McKerrow, C. B., Molyneux, M. K. B., Rossiter, C. E., and Tombleson, J. B. L. (1973). Brit.J. industr. Med., 30, 25-36. A study of the acute and chronic changes in ventilatory capacity of workers in Lancashire cotton mills. A prospective study of workers in 14 cotton and two man-made fibre spinning mills in Lancashire was carried out over a three-year period. A questionnaire on respiratory symptoms was completed at the start of the survey and again two years later. Up to six measurements of ventilatory capacity were made at six-monthly intervals. From these measurements the rate at which the forced expiratory volume $\left(\mathrm{FEV}_{1}\right)$ was declining (annual decline in FEV) was evaluated for 595 subjects. Six of the mills were visited on Mondays and in 199 operatives the ventilatory capacity was measured at both the beginning and end of the shift to evaluate its acute fall during work (Monday fall in FEV).

The mean annual decline in FEV for cotton workers was $54 \mathrm{ml} /$ year and it was only $32 \mathrm{ml} /$ year for workers in the man-made fibre mills but this lower value was attributable almost entirely to one of the two mills. For the jobs near the carding engines the annual decline was $22 \mathrm{ml} /$ year higher than for speed-frame tenters. The annual decline for cigarette smokers was $19 \mathrm{ml} /$ year greater than for non- and ex-smokers. The annual decline in FEV was not found to be related to symptoms of byssinosis or bronchitis, nor to present dust levels, bioactivity of the dust or air pollution, although the expected effect attributable to byssinosis turned out to be less than that which the survey was designed to detect.

The mean Monday fall in FEV was higher in cotton mills than in man-made fibre mills among those without symptoms of byssinosis and was correlated with present dust levels. For those with symptoms of byssinosis an increased Monday fall was found only in those processing coarse cotton.

For those subjects who completed the respiratory questionnaire on two occasions the chronic and acute changes in FEV were examined in relation to the change in symptoms of byssinosis. No association was found for annual decline in FEV but the Monday fall in FEV was greater for those who developed byssinosis during the survey than for those who remained free of symptoms, and was less for those who lost their symptoms than for those who retained them.
\end{abstract}

Previous investigations on the ventilatory capacity of cotton workers have generally shown that those workers with symptoms of byssinosis have lower values of ventilatory capacity than those without.

*Present address: Department of Social and Occupational Medicine, University of Dundee.
Schilling (1956) reported a difference of 1 litre in the forced expiratory volume over $\frac{3}{4}$ second $\left(\mathrm{FEV}_{0.75}\right)$ between normal cotton workers and those with grade 2 byssinosis but later studies have shown smaller differences, e.g., Lammers, Schilling, and Walford (1964), Batawi, Schilling, Valić, and Walford (1964), and Mekky, Roach, and Schilling 
(1967) found one of only about $0 \cdot 31$. Various explanations of these findings can be suggested; for instance, there could be a greater tendency for those with a low ventilatory capacity, for their age and height, to develop symptoms of byssinosis, or byssinosis could lead to an increased rate of decline in ventilatory capacity with time. The present paper analyses those aspects of the three-year prospective survey described by Molyneux and Tombleson (1970) bearing on this long-term decline in the ventilatory capacity ('annual decline') and its relation to the acute fall in ventilatory capacity often accompanying exposure to cotton dust after absence from it ('Monday fall'). The possibility of a relationship between these is of practical interest, as measurement of the acute fall at work in the individual might indicate liability to later permanent respiratory disability. Further, in a group of workers, the average acute decline in ventilatory capacity over a day's work might serve as a 'biological monitor' of the working environment.

\section{Population and methods}

Details of the population studied, the grading of byssinosis and bronchitis from the respiratory questionnaire, and of the measurement of dust concentrations are given by Molyneux and Tombleson (1970) but are summarized below.

The population defined comprised 1857 men and women between the ages of 15 and 65 working in the blowing, carding, and associated processes of 16 Lancashire mills, of which 8 processed coarse cotton (count 1 to 24), 6 medium cotton (count 10 to 50 ), and 2 processed man-made fibre. Of these workers, 120 either refused to co-operate or were absent and 151 could not be questioned because they knew too little English.

Fifteen of the 16 mills were visited on six occasions at six-monthly intervals thus covering a period of 30 months. The other mill, included to replace one which closed after a single visit, was visited on only five occasions over a 24-month period. On each visit lung function measurements were made on all the available workers. One thousand three hundred and forty-three workers (554 men and 789 women) were tested on between one and six occasions. The main reasons for less than six sets of measurements being made were that subjects had changed employer, were off work due to sickness, or were working on a different shift. Visits to six of the mills ( 3 processing coarse cotton, 2 medium cotton, and 1 man-made fibre) were made on Mondays and at these 199 operatives (53 men and 146 women) were measured both in the morning at the beginning of the shift and in the afternoon at its end.

The prevalence of byssinosis and bronchitis were determined by the use of a questionnaire on respiratory symptoms (Medical Research Council, 1960) to which questions on chest tightness were added (Roach and Schilling, 1960). Byssinosis was sub-divided into three grades:

Grade $\frac{1}{2}$ occasional chest tightness on Mondays
Grade I chest tightness and/or difficulty in breathing on Mondays only

Grade II chest tightness and/or difficulty in breathing on Mondays and other days.

The classification of bronchitis was based on that of the Medical Research Council (1966):

Grade 1 chronic phlegm for at least three consecutive months each year but no acute exacerbations

Grade 2 chronic phlegm, and also one attack of increased phlegm lasting three weeks or more and/or chest illness with increased phlegm causing absence from work of one week or more in the last three years

Grade 3 as grade 2 but with two or more attacks of increased phlegm and/or two or more chest illnesses.

The forced expiratory volume was taken as the mean of three successful blows after two practice ones, and was corrected to a water temperature of $20^{\circ} \mathrm{C}$. The forced vital capacity was the mean of two determinations similarly corrected for temperature. Sitting height was also measured.

The mass concentrations of the respirable, medium, and fly components of total dust were measured at sites corresponding so far as practicable to the working places of the operatives, and the modified Hexhlet and total samplers were run throughout the shifts on which the lung function measurements were made. It was therefore possible to estimate the environment in which each individual had worked, assuming that the measurement made was representative of his daily working conditions.

Indices of lung function

The following indices of lung function were considered:

(1) Forced expiratory volume over one second $\left(\mathrm{FEV}_{1}\right)_{\text {- }}$ the mean of all visits, the morning visits being taken for those seen twice on a Monday

(2) Forced vital capacity (FVC) - the mean over all visits

(3) $\mathrm{FEV}_{1} / \mathrm{FVC}^{\circ}$-the mean $\mathrm{FEV}_{1}$ as a percentage of the mean FVC

(4) Annual decline in $\mathrm{FEV}_{1}$-the slope of the line fitted by least squares to the measurements of FEV $_{1}$ plotted against time over the 30-month period; this index is expressed in $\mathrm{ml} /$ year with a decline having a positive value

(5) Monday fall in $\mathrm{FEV}_{1}$ - the mean, over all visits, of the difference between the afternoon and morning values of $F E V_{1}$ for subjects seen twice on Mondays; this index is expressed in millilitres, a positive value indicating a reduction during the shift.

Indices (1), (2), and (3) are available on the 1343 subjects measured on one or more visits, but (4) requires values from at least two visits, for which only 1001 subjects were available. The accuracy of an estimated linear decline in a series of test results is determined by the length of time between the first and last measurements, and to a lesser extent by the number of occasions on which measurements are made. Two measurements of FEV at an interval of 6 or 12 months (and, for the majority of subjects measured only twice the measurements were not more than 12 months apart) and three, covering a period of a year, give such badly determined 
annual declines that it was decided to exclude such sets of data. Therefore, a subject was included in the annual decline analysis only if he was seen at least three times covering a period of at least 18 months. This choice was optimum in the sense that the variance of the mean annual decline would have been greater if either more or less strict criteria had been adopted. Of the 642 subjects so included there were some whose FEV values showed such wide variation between occasions that little confidence could be placed in the annual decline calculation. These subjects were excluded from the annual decline analysis, and arbitrarily the line was drawn at a variance in the estimate of annual decline of $20000\left(\mathrm{ml} /\right.$ year) ${ }^{2}$. This criterion excluded 47 subjects. As would be expected, many of the subjects excluded from the annual decline analysis, because of either too few measurements or wide variation between occasions, had calculated annual declines which were abnormal. However, in no case was a subject excluded because his annual decline appeared abnormal, but only if it was poorly estimated. Thus 595 subjects ( 232 men and 363 women) remained in the annual decline study and this is $38 \%$ of the 1586 seen, or $44 \%$ of the 1343 operatives whose FEV was measured at least once. Consideration was given to allowing for a seasonal effect in estimating annual decline since McKerrow and Rossiter (1968) reported a difference between summer and winter values of $0.044 \mathrm{l}$. in $\mathrm{FEV}_{\mathbf{0 . 7 5}}$. However, for these operatives the mean seasonal effect was of the order of only 0.021 . and was not significant. Also, for the subjects seen in February and August the small seasonal effect was such that the winter value was higher than the summer value. Thus, it was not possible to establish any seasonal effect in this survey population and, if present at all, the seasonal effect would be small and of negligible importance in the calculation of annual decline.

\section{Results}

\section{Annual decline in FEV}

The annual decline in FEV has been examined in relation to the factors given below; most of these are of direct interest such as factors (4) to (7), representing the respiratory health of the individual, factors (8) to (12), representing the working environment and history, while factors (1) to (3) have been included so that their effects could be allowed for in assessing the effects of the other factors:

(1) Sex

(2) Age-in 10 five-year age groups from 15-19 to $60+$

(3) Smoking-non-smokers, ex-smokers, pipe smokers, and cigarette smokers grade 1 ( $<10$ cigarettes/day), grade 2 (10-19 cigarettes/day), and grade 3 ( 20 or more cigarettes/ day

(4) Bronchitis-nil, grade 1, grade 2, grade 3

(5) Byssinosis-nil, grade $\frac{1}{2}$, grade I, grade II

(6) FEV-low, medium, high (see below)

(7) FEV/FVC \%-less than $75 \%, 75 \%$ and over

(8) Mill type-man-made fibre, medium cotton, coarse cotton
(9) Exposure or years worked in cotton mills-in nine five-year groups from $0-4$ to $40+$ (for subjects working in cotton mills only)

(10) Occupation-10 jobs in carding and associated processes (cotton mills only)

(11) Dust concentrations-respirable $(<7 \mu$ Stokes diameter), fine ( $<2 \mathrm{~mm}$ length), total

(12) Bioactivity of dust (see below)

(13) Air pollution (see below).

The FEV (factor (6)) was classified into one of three categories according as the FEV was more than 0.251 . below the expected value, within 0.251 . of the expected value or more than 0.251 . above the expected value, where the expected value was calculated from the regression of FEV on age and sitting height for subjects in the total survey population with neither byssinosis nor bronchitis (440 women and 262 men):

$$
\begin{aligned}
& \text { females: FEV }=\frac{-0.028 \text { age }(\text { years })+}{4.25 \text { sitting height }(\mathrm{m})-0.204} \\
& \text { males: } \quad \text { FEV }=\frac{-0.034 \text { age }(\text { years })+}{6.89 \text { sitting height }(\mathrm{m})-1.571}
\end{aligned}
$$

The dust concentrations were not measured in all the areas in which the subjects worked. Concentrations are known for all except three women but for only $38 \%$ of the men. The latter figure is low partly because no dust samples were taken in the blow room and partly because an accurate estimate was difficult to obtain for men whose job entailed moving frequently from one area to another. Therefore, this factor had to be considered separately from the others which were known for all subjects.

The mean values of annual decline in FEV for each category of factors (1) to (10) are given in Table 1. The standard deviation was $89 \mathrm{ml} /$ year and the standard errors of the means based on this figure are also shown in Table 1. The age group 15-19 had a negative mean annual decline, i.e., their FEV was increasing as is to be expected in adolescents. However, as these subjects were so different from the others they have been omitted in calculating the means for the other factors and from further consideration. The effect of each factor was assessed by the method of fitting constants (Yates, 1934) in which an additive model with a constant for each category of each factor was fitted by least squares. By this method mean values can be calculated for each factor which are adjusted for the effects of the remaining factors. For both bronchitis and byssinosis no adjustment was made for FEV or FEV/FVC\%.

The adjusted means are given in Table 1 and are very similar to the unadjusted values. This is not surprising since allowing for all the above factors accounts for only $8 \cdot 7 \%$ of the total variation. 
The results given in Table 1 are summarized below.

(1) Sex-after adjustment the annual decline in FEV was $12 \mathrm{ml} /$ year greater for men than for women but this difference was not significant.

(2) Age - the relationship between annual decline and age is shown in Figure 1. Apart from the 15-19 year group already commented on, there was no clear relationship between age and annual decline. The 20-24 year group had the highest decline but this

TABLE 1

Mean Annual Decline in FEV 1

\begin{tabular}{|c|c|c|c|c|c|}
\hline \multicolumn{3}{|c|}{ Factor/Category } & $\begin{array}{c}\text { No. } \\
\text { of } \\
\text { subjects }\end{array}$ & $\begin{array}{c}\text { Mean annual } \\
\text { decline in FEV } \\
\text { (ml/year) and } \\
\text { standard error }\end{array}$ & $\begin{array}{c}\text { Adjusted }^{2} \\
\text { mean } \\
\text { annual } \\
\text { decline } \\
\text { in FEV }\end{array}$ \\
\hline $\begin{array}{l}\text { Female } \\
\text { Male }\end{array}$ & $\begin{array}{l}\cdots \\
\cdots\end{array}$ & $\begin{array}{l}\cdots \\
\cdots\end{array}$ & $\begin{array}{l}351 \\
220\end{array}$ & $\begin{array}{l}48\left( \pm \frac{5}{ \pm}\right. \\
55( \pm \quad 6)\end{array}$ & $\begin{array}{l}46 \\
58\end{array}$ \\
\hline $\begin{array}{l}\text { Age } \\
15-19 \\
20-24 \\
25-29 \\
30-34 \\
35-39 \\
40-44 \\
45-49 \\
50-54 \\
55-59 \\
60+\end{array}$ & $\begin{array}{l}\cdots \\
\cdots \\
\cdots \\
\cdots \\
\cdots \\
\cdots \\
\cdots \\
\cdots\end{array}$ & $\begin{array}{l}\cdots \\
\cdots \\
\cdots \\
\cdots \\
\cdots \\
\cdots \\
\cdots \\
\cdots\end{array}$ & $\begin{array}{r}241 \\
19 \\
26 \\
52 \\
64 \\
74 \\
83 \\
113 \\
101 \\
39\end{array}$ & $\begin{array}{r}-35( \pm 18) \\
82( \pm 20) \\
46( \pm 17) \\
44( \pm 12) \\
43( \pm 11) \\
58( \pm 10) \\
45( \pm 10) \\
35( \pm 8) \\
67( \pm 9) \\
59( \pm 14)\end{array}$ & $\begin{array}{l}- \\
90 \\
55 \\
47 \\
43 \\
55 \\
42 \\
33 \\
67 \\
63\end{array}$ \\
\hline $\begin{array}{l}\text { Smoking } \\
\text { Non } \\
\text { Ex } \\
\text { Pipe } \\
\text { Grade }\end{array}$ & $\begin{array}{l}\cdots \\
\cdots \\
\cdots \\
2 \\
3\end{array}$ & $\begin{array}{l}\cdots \\
\cdots \\
\cdots \\
\cdots \\
\cdots\end{array}$ & $\begin{array}{r}193 \\
47 \\
22 \\
187 \\
104 \\
18\end{array}$ & $\begin{array}{l}40( \pm 6) \\
39( \pm 13) \\
52( \pm 19) \\
58( \pm 7) \\
60( \pm 9) \\
60( \pm 21)\end{array}$ & $\begin{array}{l}40 \\
33 \\
47 \\
61 \\
58 \\
61\end{array}$ \\
\hline $\begin{array}{l}\text { Bronchitis } \\
\text { Nil } \\
\text { Grade }\end{array}$ & $\begin{array}{l}s \\
1 \\
2 \\
3\end{array}$ & $\begin{array}{l}\cdots \\
\cdots \\
\cdots\end{array}$ & $\begin{array}{r}375 \\
120 \\
50 \\
26\end{array}$ & $\begin{array}{l}53( \pm 5) \\
50( \pm 8) \\
36( \pm 13) \\
49( \pm 17)\end{array}$ & $\begin{array}{l}54 \\
53 \\
27 \\
37\end{array}$ \\
\hline $\begin{array}{l}\text { Byssinosis } \\
\text { Nil } \\
\text { Grade }\end{array}$ & $\begin{array}{l}s \\
\frac{1}{2} \\
\text { II }\end{array}$ & $\begin{array}{l}\cdots \\
\cdots \\
\cdots\end{array}$ & $\begin{array}{r}426 \\
38 \\
75 \\
32\end{array}$ & $\begin{array}{l}50( \pm 4) \\
48( \pm 14) \\
59( \pm 10) \\
45( \pm 16)\end{array}$ & $\begin{array}{l}51 \\
46 \\
56 \\
41\end{array}$ \\
\hline $\begin{array}{l}F E V \\
\text { Low } \\
\text { Mediun } \\
\text { High }\end{array}$ & & $\begin{array}{l}\cdots \\
\cdots \\
\cdots\end{array}$ & $\begin{array}{l}190 \\
253 \\
128\end{array}$ & $\begin{array}{l}50( \pm 6) \\
51( \pm 6) \\
52( \pm 8)\end{array}$ & $\begin{array}{l}47 \\
52 \\
53\end{array}$ \\
\hline $\begin{array}{r}F E V \mid F V C \\
<75 \% \\
\geqslant 75 \%\end{array}$ & & $\begin{array}{l}\cdots \\
\cdots\end{array}$ & $\begin{array}{l}339 \\
232\end{array}$ & $\begin{array}{l}52( \pm 5) \\
48( \pm 6)\end{array}$ & $\begin{array}{l}53 \\
47\end{array}$ \\
\hline
\end{tabular}

TABLE 1-continued

\begin{tabular}{|c|c|c|c|}
\hline Factor/Category & $\begin{array}{c}\text { No. } \\
\text { of } \\
\text { subjects }\end{array}$ & $\begin{array}{l}\text { Mean annual } \\
\text { decline in FEV } \\
\text { (ml/year) and } \\
\text { standard error }\end{array}$ & $\begin{array}{c}\text { Adjusted }^{2} \\
\text { mean } \\
\text { annual } \\
\text { decline } \\
\text { in FEV }\end{array}$ \\
\hline $\begin{array}{l}\text { Mill type } \\
\text { Man-made fibre } \\
\text { Medium cotton } \\
\text { Coarse cotton.. }\end{array}$ & $\begin{array}{r}81 \\
193 \\
297\end{array}$ & 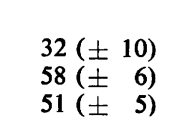 & $\begin{array}{l}31 \\
62 \\
48\end{array}$ \\
\hline 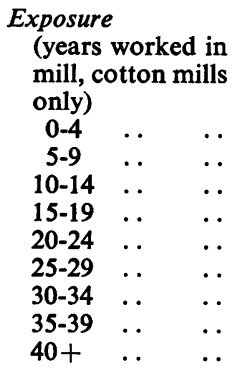 & $\begin{array}{l}31 \\
46 \\
72 \\
96 \\
49 \\
52 \\
42 \\
50 \\
52\end{array}$ & $\begin{array}{l}81( \pm 16) \\
33( \pm 13) \\
50( \pm 11) \\
48( \pm 9) \\
54( \pm 13) \\
66( \pm 12) \\
52( \pm 14) \\
48( \pm 13) \\
64( \pm 12)\end{array}$ & $\begin{array}{l}70 \\
24 \\
50 \\
47 \\
57 \\
66 \\
62 \\
59 \\
59\end{array}$ \\
\hline 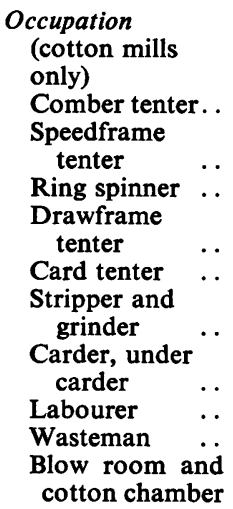 & $\begin{array}{r}17 \\
171 \\
41 \\
50 \\
34 \\
63 \\
40 \\
19 \\
7 \\
48\end{array}$ & $\begin{array}{l}33( \pm 22) \\
45( \pm 7) \\
66( \pm 14) \\
67( \pm 13) \\
66( \pm 15) \\
67( \pm 11) \\
64( \pm 14) \\
63( \pm 20) \\
61( \pm 34) \\
28( \pm 13)\end{array}$ & $\begin{array}{l}35 \\
46 \\
74 \\
79 \\
71 \\
59 \\
1 \\
61 \\
53 \\
49 \\
20\end{array}$ \\
\hline
\end{tabular}

${ }^{1}$ These adolescent subjects excluded from the means of the other factors.

${ }^{2}$ Adjusted by method of fitting constants for other factors (see text).

value was not significantly greater than that of those aged 25 or more $(t=1.58, \mathrm{P}>0.05)$. However, further comment on this finding is included in the discussion section.

(3) Smoking - current cigarette smokers had a mean annual decline $19 \mathrm{ml} /$ year greater than non- and ex-smokers $(t=2.42, \mathrm{P}<0.02)$ but there was no trend with amount of tobacco consumption.

(4) Bronchitis-the bronchitics of grades 2 and 3 had lower mean annual declines than the nonbronchitics, particularly after adjustment when the difference was significant at the $5 \%$ level $(t=1.97)$. 


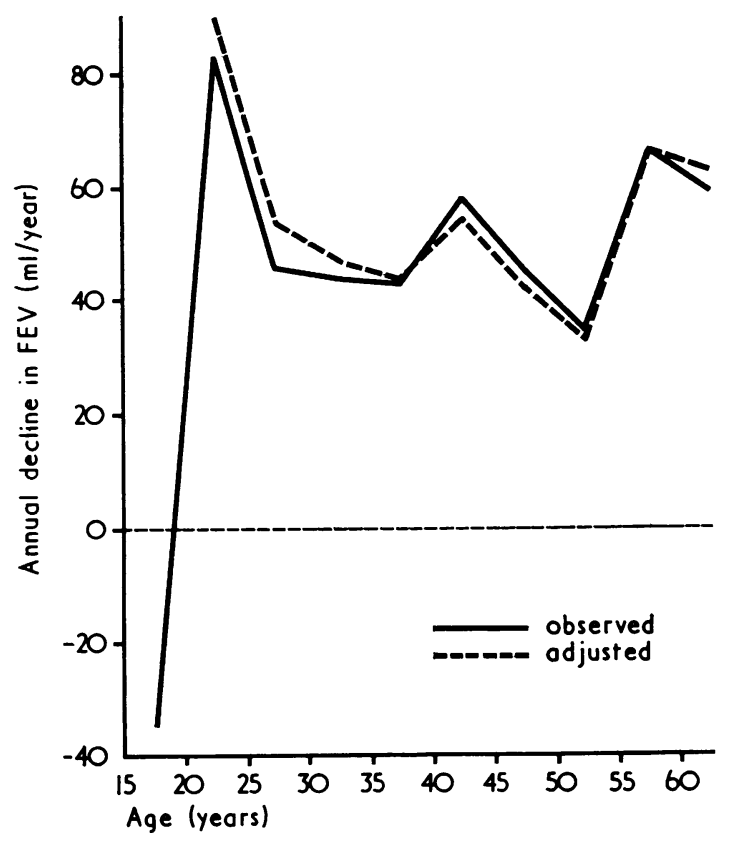

FIG. 1. Relationship between annual decline in FEV and age. The adjusted figures were obtained by the method of fitting constants and make allowance for various other factors (see text).

(5) Byssinosis-those with byssinosis had mean annual declines similar to those without byssinosis.

(6) and (7) Lung function-there was little evidence that annual decline was related to FEV or to $\mathrm{FEV} / \mathrm{FVC} \%$.

(8) Mill type-there was little difference between the mean values for the coarse and medium cotton mills, even though the former were more dusty. The mean for the man-made fibre mills was $22 \mathrm{ml} /$ year less than the mean of all cotton mills $(t=2 \cdot 07$, $P<0.05)$.

(9) Exposure-the relationship between annual decline and length of exposure for cotton workers is shown in Figure 2. The highest value occurred in the 0-4 year group and although this was partly a reflection of the age effect this group still has the highest mean after adjustment. Between 5 and 30 years there was an upward trend of annual decline followed by a plateau. However, none of these observations was statistically significant.

(10) Occupation-this is considered below in relation to dust concentration.

As the factors considered above contribute so little to the variation in annual decline in the further analysis it was not necessary to make any allowance for them.

The relationship between annual decline and dust

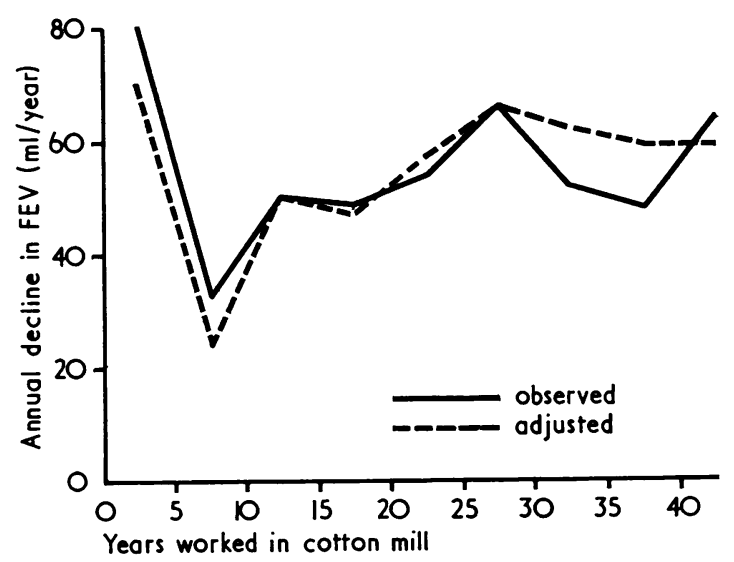

FIG. 2. Relationship between annual decline in FEV and years worked in cotton mill. The adjusted figures were obtained by the method of fitting constants and make allowance for various other factors (see text).

concentrations has been examined by dividing each of the three components, respirable, fine, and total, into six ranges and the mean annual declines and standard errors for each are shown in Table 2. No relationship between annual decline and dust concentration is shown and, since the coarse mills were

TABLE 2

mean annual Decline in FEV $_{1}$ and Dust Concentration in Cotton Mills

\begin{tabular}{l|c|c|c}
\hline Component & $\begin{array}{c}\text { Concentration } \\
\left(\mathrm{mg} / \mathrm{m}^{3}\right)\end{array}$ & $\begin{array}{c}\text { No. of } \\
\text { subjects }\end{array}$ & $\begin{array}{c}\text { Mean annual } \\
\text { decline in FEV } \\
\text { (ml/year) and } \\
\text { standard error }\end{array}$ \\
\hline \multirow{5}{*}{ Respirable } & $0 \cdot 11-0 \cdot 19$ & 29 & $64( \pm 17)$ \\
& $0 \cdot 20-0 \cdot 29$ & 93 & $54( \pm 9)$ \\
& $0 \cdot 30-0 \cdot 39$ & 27 & $59( \pm 17)$ \\
& $0 \cdot 40-0 \cdot 49$ & 120 & $57( \pm 8)$ \\
& $0 \cdot 50-0 \cdot 69$ & 40 & $39( \pm 14)$ \\
& $0 \cdot 70-1 \cdot 41$ & 64 & $57( \pm 11)$ \\
\hline & $0 \cdot 25-0 \cdot 49$ & 65 & $58( \pm 11)$ \\
& $0 \cdot 50-0 \cdot 74$ & 84 & $55( \pm 10)$ \\
& $0 \cdot 75-0 \cdot 99$ & 77 & $58( \pm 10)$ \\
& $1 \cdot 00-1 \cdot 24$ & 55 & $57( \pm 12)$ \\
& $1 \cdot 25-1 \cdot 49$ & 70 & $50( \pm 11)$ \\
& $1 \cdot 50-2 \cdot 38$ & 22 & $45( \pm 19)$ \\
\hline \multirow{5}{*}{ Fotal } & $0 \cdot 67-0 \cdot 99$ & 90 & $62( \pm 9)$ \\
& $1 \cdot 00-1 \cdot 49$ & 74 & $46( \pm 10)$ \\
& $1 \cdot 50-1 \cdot 99$ & 40 & $77( \pm 14)$ \\
& $2 \cdot 00-2 \cdot 74$ & 52 & $59( \pm 12)$ \\
& $2 \cdot 75-3 \cdot 49$ & 62 & $63( \pm 11)$ \\
& $3 \cdot 50-7 \cdot 20$ & 55 & $27( \pm 12)$ \\
& & & \\
\hline
\end{tabular}


between two and three times as dusty as the medium mills, this corresponds with the similarity of the mean values of annual decline for medium and coarse mills shown in Table 1.

Turning now to occupation, the first six jobs in Table 1 are arranged in order of their mean dust concentrations. The mean fine dust concentrations for the jobs are $0 \cdot 4,0 \cdot 8,1 \cdot 0,1 \cdot 0,1 \cdot 2$, and $1 \cdot 2 \mathrm{mg} / \mathrm{m}^{3}$. The mean annual decline in FEV for the least dusty job (comber tenter) was only $33 \mathrm{ml} /$ year and for the next dusty job (speedframe tenter) was $45 \mathrm{ml} /$ year compared with means of 66 or $67 \mathrm{ml} /$ year for the dustier jobs (ring spinner, drawframe tenter, card tenter, stripper, and grinder). The difference in the annual decline between the two least dusty jobs and the four dustier jobs was significant $(t=2 \cdot 45, \mathrm{P}<$ 0.02 ). At first sight this finding seems contradictory to the lack of a positive relationship between annual decline and fine dust concentration. This was explored further by examining the relation of fine dust concentration and annual decline within occupation groups. Of the four jobs, stripper and grinder, card tenter, drawframe tenter, and speedframe tenter, the first two involve work on the carding engine, from which, in the normal sequence of processing, the cotton is transferred to the drawframes and then to the speedframes. Hence these jobs represent a sequence of processing operations as well as of dust levels. In Fig. 3 are shown the relationships of annual decline and fine dust concentration for the first three jobs combined and for speedframe tenters. Within the two job groups there was a negative association with dust level, although these associations were not

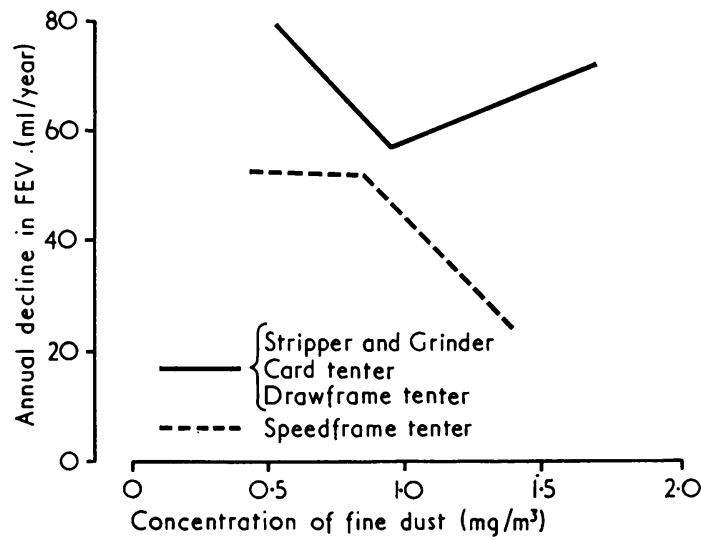

FIG. 3. Relationship between annual decline in FEV and concentration of fine dust ( $<2 \mathrm{~mm}$ length) for two groups of cardroom occupations.

significant, and the jobs on or near the carding engines had higher annual declines than the speedframe tenters. The mean difference of $22 \mathrm{ml} /$ year was significant at the $5 \%$ level $(t=2 \cdot 20)$. Possible interpretations of these findings are given in the discussion section.

In Table 3 are given the mean annual declines and standard errors, a measure of bioactivity, and an index of air pollution for each mill separately. The bioactivity (smooth muscle contraction) of the dust

TABLE 3

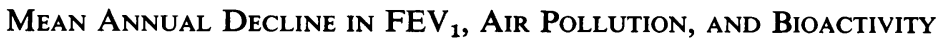

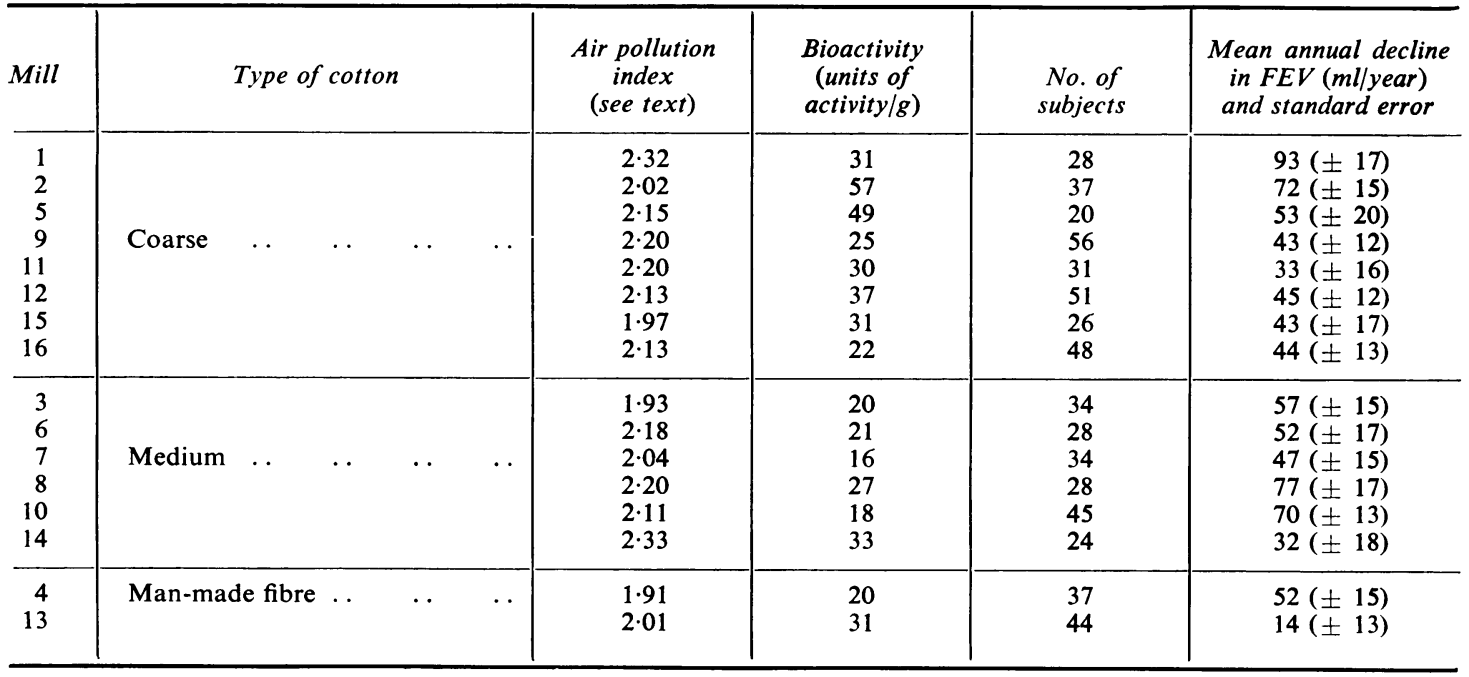


was measured relative to a standard preparation of dust using guinea-pig ileum as test preparation. A single air pollution index was obtained by calculating the mean, after transforming to logs, of the smoke and sulphur dioxide determinations $\left(\mathrm{mg} / \mathrm{m}^{3}\right)$ made on each of the six visits to a mill. Mills 1 to 8 were visited in October/November and April/May and mills 9 to 16 in January/February and July/August, and the means are therefore not comparable between these two sets. For five sites in the National Air Pollution Survey, which were in the area of the mills, for the years 1964 to 1967 (Ministry of Technology, 1964, $1965,1966,1967)$ the November/May means were higher than the February/August means by between 0.07 and 0.16 with a mean of $0 \cdot 10$. This has been allowed for in the air pollution index by adding $0 \cdot 05$ to the means of mills 9 to 16 and subtracting the same amount for mills 1 to 8 . An attempt was made to make more use of the data of the National Air Pollution Survey but only half of the mills were within one mile of a site regularly used during the period of the survey and these data were not considered further.

The bioactivity of the dust was generally higher in the coarse mills than in the medium mills. The positive values for the two man-made fibre mills indicate that the test is not specific to cotton. There was no relationship between annual decline in FEV and bioactivity.

There was also no clear relationship between annual decline and the air pollution index. Mills 1 and 14 had the two highest air pollution indices and the highest and lowest annual declines respectively in the cotton mills, and plotting out the figures for all 14 cotton mills showed no overall trend.

The mean annual declines for the two man-made fibre mills were dissimilar. In mill 4 the mean was about equal to the mean for the whole study whilst in mill 13 the lowest mean decline of all the mills was found. In view of this, the difference between the mean declines for workers in cotton mills and workers in man-made fibre mills previously noted to be significant must carry less weight.

\section{Monday fall in FEV}

The mean Monday fall in FEV related to type of mill and byssinosis is given in Table 4 and individual values subdivided by the same two factors are shown in Figure 4. The main characteristics are first the importance of mill type in determining difference among those without byssinosis, the negligible mean fall in the man-made fibre mills being significantly less $(t=3.11, \mathrm{P}<0.01)$ than the fall of $85 \mathrm{ml}$ in the medium cotton mills although this value was only significantly different from the larger fall of $126 \mathrm{ml}$ in the coarse cotton mills at about the $10 \%$ level $(t=1 \cdot 63)$. Secondly, the Monday fall was related to symptoms of byssinosis only in the coarse cotton mills. The largest value observed in the man-made fibre mills was $160 \mathrm{ml}$, but in the medium mills 8 out of 43 workers without byssinosis had a fall of more than $200 \mathrm{ml}$ and in the coarse mills the corresponding proportion was 18 out of 77 . For those with byssinosis, combining all grades, 2 out of 17 subjects in the medium mills and 12 out of 30 subjects in the coarse mills had a fall of more than $200 \mathrm{ml}$. Hence, the relationship between Monday fall and byssinosis was not strong, an appreciable proportion of nonbyssinotics exposed to cotton dust having a large fall and conversely a high proportion of byssinotics having only a small one.

The Monday fall was not significantly related to sex, age, length of exposure, smoking, and lung function. For workers in cotton mills without byssinosis or with byssinosis of only grade $\frac{1}{2}$ there was a relationship between Monday fall and bronchitis. The 33 subjects with bronchitis had a mean fall of $140 \mathrm{ml}$ compared with $97 \mathrm{ml}$ for the 100 nonbyssinotics. However, even this finding was not significant at the $10 \%$ level $(t=1 \cdot 61)$.

The relationships between Monday fall and dust concentration were also examined for non and grade $\frac{1}{2}$ byssinotics only, so that they represent an effect independent of the weak relationship of Monday fall and byssinosis. Workers in man-made fibre mills were taken as exposed to a zero level of dust. One hundred and thirty-seven subjects contri-

TABLE 4

Mean Monday Fall in FEV 1 , Type of Mill, and Byssinosis

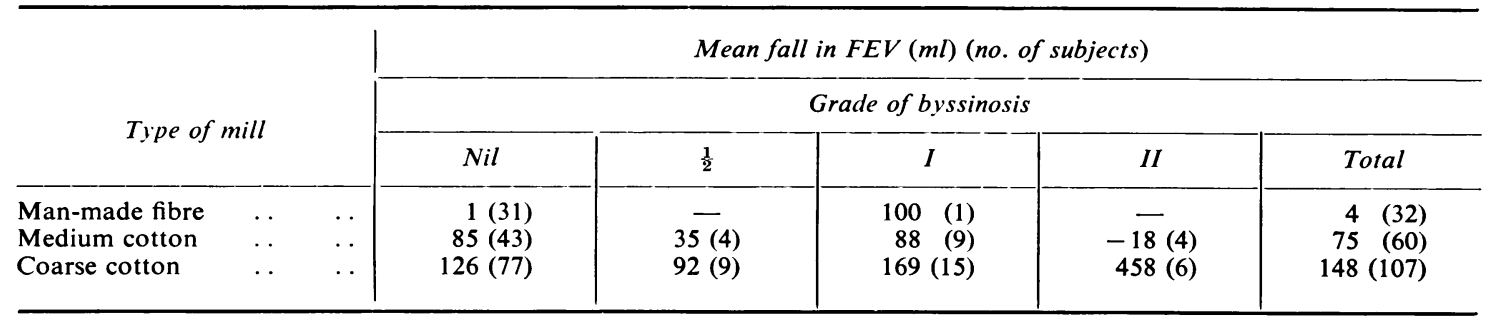




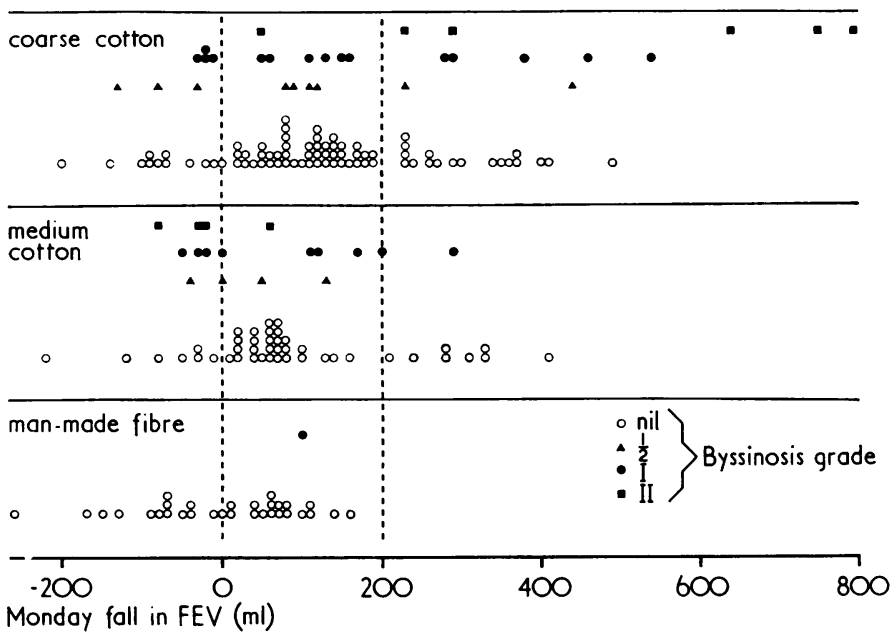

FIG. 4. Monday fall in FEV for each individual classified by symptoms of byssinosis and type of fibre worked with. buted to the relationships. The correlation coefficients between Monday fall and the components of dust were: respirable dust 0.328 , fine 0.344 , and total dust 0.347 , all being significant $(P<0.001)$. The relationship with fine dust concentration is illustrated in Fig. 5 where each point is the mean for workers exposed to similar concentrations, the component having been divided into the six ranges shown in Table 2 (except that the highest two ranges were combined).

Of these 137 workers, there were 90 for whom an estimate of annual decline in FEV was available. The correlation coefficient between Monday fall and annual decline in FEV was -0.132. This was not significant $(P>0.1)$ and was negative, whereas it would be expected to be positive.

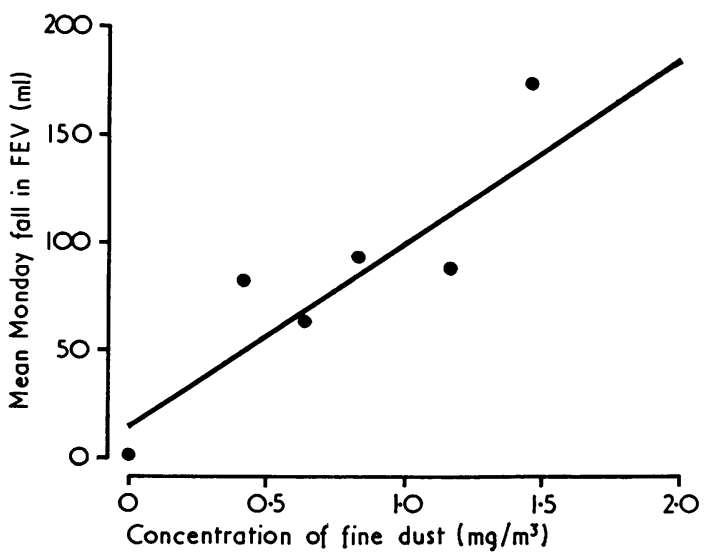

FIG. 5. Relationship of Monday fall in FEV to concentration of fine dust ( $<2 \mathrm{~mm}$ length) for subjects without byssinosis or with byssinosis of grade $\frac{1}{2}$ only.

\section{Change of symptoms of byssinosis}

The questionnaire on respiratory symptoms was completed on a second occasion, two years after the first, for all subjects followed up over this period. Molyneux and Tombleson (1970) commented on the changes in grade of byssinosis over the two-year period and we have now examined whether there was any relationship between the changes in grade and either annual decline in FEV or Monday fall in FEV. These two indices are given in Table 5 classified by the grades of byssinosis on the two occasions for workers in cotton mills. Because of small numbers in some of the combinations of grades, we have reduced the byssinosis scale to a dichotomy by including grade $\frac{1}{2}$ with non-byssinotics and combining grades I and II. There was no tendency for those workers whose byssinosis progressed to have higher annual declines; in fact those who progressed from grades nil or $\frac{1}{2}$ to I or II had lower values than those who remained in grades nil or $\frac{1}{2}$, but the difference was not significant. Those originally in grades I or II who regressed had lower annual declines than those who remained in grades I or II but again this was not significant. For Monday fall in FEV a much clearer picture emerged; those originally in grades $\mathrm{nil} / \frac{1}{2}$ who progressed had a mean Monday fall double of those who did not progress $(P<0.01, t=2.82)$ and those originally in grades I or II who regressed had a mean Monday fall of $26 \mathrm{ml}$ compared with $433 \mathrm{ml}$ for those who remained in grades I or II $(\mathrm{P}<0.001, t=5 \cdot 13)$.

\section{Discussion}

We shall first consider the appropriateness of analysing absolute changes in FEV. We chose to study changes in FEV because byssinosis was known to be associated with lower levels of FEV and with 
TABLE 5

Mean Annual Decline in FEV , Mean Monday Fall in FEV $_{1}$, and Byssinosis Grade ON Two OCCASIONS FOR WORKERS IN COTTON MILLS

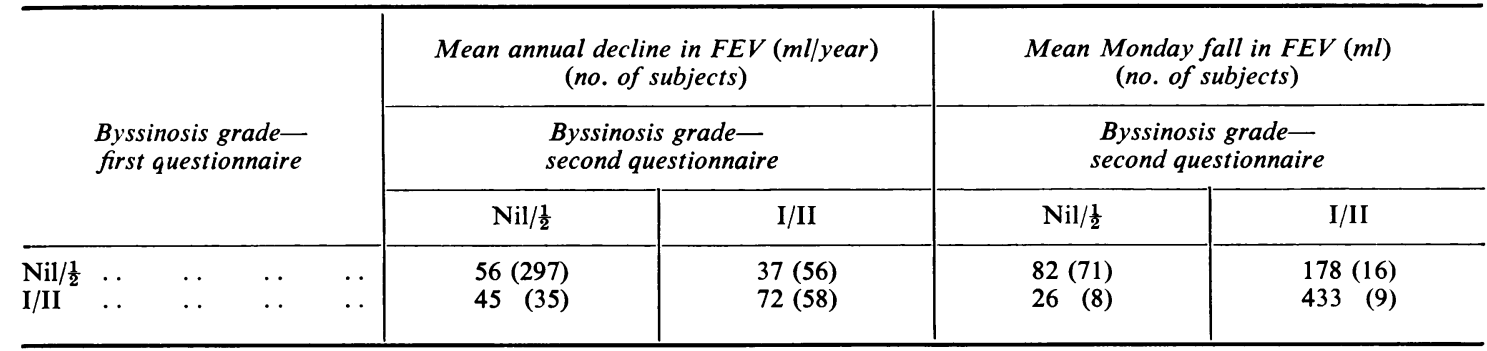

a Monday change in FEV and these known associations were the starting points of the study. The reason that we chose to calculate annual decline in FEV in absolute terms was not so definite. It could be argued that it would be more reasonable to calculate the decline relative to the mean level of FEV since the effects of exposure to some agent might be expected to result in a proportional change in ventilatory capacity. Whether or not this is so depends on the pattern of decline in non-exposed and exposed populations and there appears to be little information on this aspect. As a safeguard, therefore, an analysis was also carried out of the annual decline relative to the mean FEV but this did not appear to add anything to the analysis of absolute decline or to simplify the interpretation, and hence details are not given in this paper.

We now consider in what ways our study may have produced results differing from those of previously reported epidemiological studies in cotton mills. The mills included were selected because they used the coarser grades of cotton and were likely to remain in operation during the three years of the study. Neither of these requirements should have reduced the incidence or severity of disease found. Of more importance was the fact that less than half of the subjects who were seen at some time during the survey were seen sufficiently often for a reasonable estimate of annual decline in FEV to be made. We should therefore consider how representative those subjects in the 'annual decline' population are of the total population. First the 'annual decline' population will not include anyone who worked in the industry for less than 18 months; in fact only $10 \%$ of the 'annual decline' population had less than five years' exposure compared with $22 \%$ of the total cotton mill population seen. For the same reason the 'annual decline' population had a mean age 4 years older than the total cotton mill population. Secondly, we might expect that the 'annual decline' population would be deficient in workers in relatively poorer health since these workers would be more likely to be off work when visits to the mill were made. In Table 6 the prevalences of byssinosis and bronchitis

TABLE 6

Prevalence ( $\%$ ) of Byssinosis and Bronchitis in Cotton Mills for Total Population and Annual Decline Population

\begin{tabular}{|c|c|c|c|c|c|c|c|c|}
\hline & & & & & \multicolumn{2}{|c|}{ Females } & \multicolumn{2}{|c|}{ Males } \\
\hline & & & & & $\begin{array}{c}\text { Total } \\
\text { population }\end{array}$ & $\begin{array}{c}\text { Annual } \\
\text { decline } \\
\text { population }\end{array}$ & $\begin{array}{c}\text { Total } \\
\text { population }\end{array}$ & $\begin{array}{c}\text { Annual } \\
\text { decline } \\
\text { population }\end{array}$ \\
\hline $\begin{aligned} \text { Byssinosis grade } & \frac{1}{2} \\
& \text { I } \\
& \text { II } \\
& \text { Total }\end{aligned}$ & $\begin{array}{l}\cdots \\
\cdots \\
\cdots \\
\cdots\end{array}$ & $\begin{array}{l}\cdots \\
\cdots \\
\cdots \\
\cdots\end{array}$ & $\begin{array}{l}\cdots \\
\cdots \\
\cdots \\
\cdots\end{array}$ & $\begin{array}{l}\cdots \\
\cdots \\
\cdots \\
\cdots\end{array}$ & $\begin{array}{r}6 \cdot 7 \\
12 \cdot 7 \\
6 \cdot 2 \\
25 \cdot 6\end{array}$ & $\begin{array}{r}6 \cdot 3 \\
11 \cdot 3 \\
5 \cdot 3 \\
23 \cdot 0\end{array}$ & $\begin{array}{r}6 \cdot 9 \\
13 \cdot 8 \\
7 \cdot 6 \\
28 \cdot 3\end{array}$ & $\begin{array}{r}10 \cdot 0 \\
20 \cdot 5 \\
7 \cdot 9 \\
38 \cdot 4\end{array}$ \\
\hline $\begin{aligned} & \text { Bronchitis grade } 1 \\
& 2 \\
& 3 \\
& \text { Total }\end{aligned}$ & $\begin{array}{l}\cdots \\
\cdots \\
\cdots \\
\cdots\end{array}$ & $\begin{array}{l}\cdots \\
\cdots \\
\cdots \\
\cdots\end{array}$ & $\begin{array}{l}\cdots \\
\cdots \\
\cdots \\
\cdots\end{array}$ & $\begin{array}{l}\cdots \\
\cdots \\
\cdots \\
\cdots\end{array}$ & $\begin{array}{r}15 \cdot 0 \\
7 \cdot 7 \\
6 \cdot 8 \\
29 \cdot 5\end{array}$ & $\begin{array}{r}18 \cdot 3 \\
10 \cdot 0 \\
3 \cdot 7 \\
32 \cdot 0\end{array}$ & $\begin{array}{r}27 \cdot 7 \\
8 \cdot 5 \\
6 \cdot 9 \\
43 \cdot 1\end{array}$ & $\begin{array}{r}24 \cdot 7 \\
8 \cdot 9 \\
6 \cdot 8 \\
40 \cdot 5\end{array}$ \\
\hline
\end{tabular}


are shown for the two populations. The byssinosis prevalences are similar for females but for males there is an excess of byssinosis of grades $\frac{1}{2}$ and 1 in the 'annual decline' population. Part of this excess is attributable to the absence of short-term workers in the 'annual decline' population. The bronchitis prevalences are similar for men but there is a deficiency of grade 3 bronchitic females in the 'annual decline' population. The standardized mean FEVs are shown in Table 7 for the grades of byssinosis and bronchitis. The decrease in FEV with increasing grade of byssinosis shows up well in the total population with a mean difference between non-byssinotics and grade II byssinotics of $0.20 \mathrm{l}$. for women and $0.26 \mathrm{l}$. for men. For the 'annual decline' population the situation is similar for the males but the females with byssinosis of grade II included in the 'annual decline' population have a mean FEV 0.5 1. higher than those not included. There is no clear trend of FEV with bronchitis grade for females but for males there is a difference of $0.54 \mathrm{l}$. between non-bronchitics and grade 3 bronchitics in the total population. This trend is not so marked in the 'annual decline' population due to the bronchitics of grade 3 having a mean FEV 0.35 1. higher than those excluded. Summarizing, the prevalence of disease in the 'annual decline' population is a little less than in the total population seen, and this is reflected in a smaller decrease in FEV with byssinosis in the 'annual decline' population.

A further factor possibly affecting a comparison of the relation of absolute value of FEV to byssinosis grade is exposure to dust at the time of testing. There is little doubt that environmental conditions have improved since the surveys of Schilling, Hughes, Dingwall-Fordyce, and Gilson (1955). As tests were then made during the working day, the values measured must have included some component of acute response to the cotton dust and this will have been more marked in those with byssinosis. A similar criticism applies to our observations but improved environmental conditions will make the effect less severe.

The analysis of annual decline will be considered first in the whole population, secondly in relation to age and length of exposure, thirdly in relation to grade of byssinosis and bronchitis, type of fibre, dust level, and occupation, and finally in relation to the influence of smoking.

The mean annual decline was $51 \mathrm{ml} / \mathrm{year}$. This is the same as was found for non-miners by Higgins and Oldham (1962) after converting $\mathrm{FEV}_{\mathbf{0 . 7 5}}$ to $\mathrm{FEV}_{1}$ by the formula given by McKerrow, McDermott, and Gilson (1960) but about $25 \mathrm{ml} /$ year greater than that reported by Fletcher, Peto, Speizer, and Tinker (1970) for men in a study on the development of early bronchitis and about $10 \mathrm{ml} /$ year greater than that found by Higgins et al. (1968) for men in Staveley (Derbyshire), allowing, as far as possible, for the different smoking and age distributions in these last two studies. The absolute level of decline is of course dependent on the same technical standards being maintained throughout. A drift in the co-operation of the subjects resulting in a decline in FEV of only 0.051 . over the period of the byssinosis survey would increase the annual decline by $20 \mathrm{ml} /$ year. Such a drift cannot be ruled out although the FEV is dependent on the subjects' co-operation chiefly to the extent of their taking a full breath and not on the amount of effort they make in the expiration (McKerrow, 1960).

The standard deviation of annual decline was

T ABLE 7

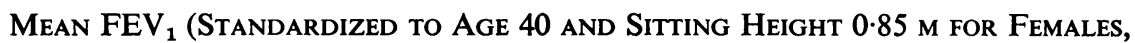
0.90 m for Males) for Total Population and Annual Decline Population

\begin{tabular}{|c|c|c|c|c|c|c|c|c|}
\hline & & & & & \multicolumn{4}{|c|}{ Mean FEV (no. of subjects) } \\
\hline & & & & & \multicolumn{2}{|c|}{ Females } & \multicolumn{2}{|c|}{ Males } \\
\hline & & & & & $\begin{array}{c}\text { Total } \\
\text { population }\end{array}$ & $\begin{array}{c}\text { Annual } \\
\text { decline } \\
\text { population }\end{array}$ & $\begin{array}{c}\text { Total } \\
\text { population }\end{array}$ & $\begin{array}{c}\text { Annual } \\
\text { decline } \\
\text { population }\end{array}$ \\
\hline $\begin{aligned} & \text { Byssinosis grade } \text { Nil } \\
& \frac{1}{2} \\
& \text { I } \\
& \text { II }\end{aligned}$ & $\begin{array}{l}\cdots \\
\cdots \\
\cdots \\
\cdots\end{array}$ & $\begin{array}{l}\cdots \\
\cdots \\
\cdots \\
\cdots\end{array}$ & $\begin{array}{l}\cdots \\
\cdots \\
\cdots \\
\cdots\end{array}$ & $\begin{array}{l}\cdots \\
\cdots \\
\cdots \\
\cdots\end{array}$ & $\begin{array}{l}2 \cdot 26(607) \\
2 \cdot 14 \quad(51) \\
2 \cdot 14 \quad(92) \\
2 \cdot 06(39)\end{array}$ & $\begin{array}{ll}2 \cdot 25 & (281) \\
2 \cdot 10 & (19) \\
2 \cdot 13 & (35) \\
2 \cdot 35 & (17)\end{array}$ & $\begin{array}{lr}3.22 & (417) \\
3.04 & (31) \\
2.96 & (71) \\
2.96 & (35)\end{array}$ & $\begin{array}{ll}3 \cdot 20 & (146) \\
3 \cdot 10 & (19) \\
2 \cdot 91 & (40) \\
2.96 & (15)\end{array}$ \\
\hline $\begin{array}{r}\text { Bronchitis grade } \text { Nil } \\
1 \\
2 \\
3\end{array}$ & $\begin{array}{l}\cdots \\
\cdots \\
\cdots \\
\cdots\end{array}$ & $\begin{array}{l}\cdots \\
\cdots \\
\cdots \\
\cdots\end{array}$ & $\begin{array}{l}\cdots \\
\cdots \\
\cdots \\
\cdots\end{array}$ & $\begin{array}{l}\cdots \\
\cdots \\
\cdots \\
\cdots\end{array}$ & $\begin{array}{l}2 \cdot 25(569) \\
2 \cdot 27(116) \\
2 \cdot 05 \quad(62) \\
2 \cdot 18 \quad(42)\end{array}$ & $\begin{array}{l}2 \cdot 25(244) \\
2 \cdot 26(63) \\
2 \cdot 04(33) \\
2 \cdot 19(12)\end{array}$ & $\begin{array}{l}3 \cdot 24(338) \\
3 \cdot 13(140) \\
2 \cdot 91(47) \\
2 \cdot 70(29)\end{array}$ & $\begin{array}{l}3 \cdot 20(132) \\
3 \cdot 10(57) \\
2 \cdot 80(17) \\
2 \cdot 88(14)\end{array}$ \\
\hline
\end{tabular}


$89 \mathrm{ml} /$ year. The variation in annual decline is made up of two components, first, the variation in measuring FEV on an occasion and, secondly, the variation of the actual annual decline between subjects. For the 344 subjects whose FEV was measured at least on visits $1,2,5$, and 6 , the standard deviation about the regression on time was $114 \mathrm{ml}$ and the variation between subjects after eliminating the former variation had a standard deviation of $61 \mathrm{ml} /$ year. From this it can be calculated that about half of the variation in annual decline found in the survey arose from the variation in measuring the FEV. Precautions were taken to keep the technical error as low as possible; each subject was seen by the same observer on the same day of the week and at approximately the same time of day on each visit. The standard deviation about the regressions of $114 \mathrm{ml}$ is within the range of other studies; e.g., McKerrow and Rossiter (1968) found a value of $82 \mathrm{ml}$ and Fletcher et al. (1970) one of about $150 \mathrm{ml}$. Therefore no considerable improvement could have been achieved except by following the workers for a longer period.

Although the mean annual decline in FEV did not differ significantly between either age groups or length of exposure groups (Table 1), the mean for age group 20-24 was higher than for the other age groups and also the 0-4 year exposure group has a higher mean than those exposed for longer. In fact the eight subjects in cotton mills aged 20-24 and with less than five years' exposure had a mean annual decline of $126 \mathrm{ml} /$ year compared with $35 \mathrm{ml} /$ year for those of the same age but longer exposure, and $65 \mathrm{ml} /$ year for older subjects with less than five years' exposure. Since within the age group 20-24 a level ventilatory capacity and not one declining with age would be expected (Lawther, Brooks, and Waller, 1970) and the 20-24 year group had a significant $(P<0.01)$ decline in FEV, this finding emphasizes the need for a prospective study of a group of new entrants to the industry.

From Table 7 there is a difference in mean FEV of $0.20 \mathrm{l}$. for females and $\mathbf{0 . 2 6} \mathrm{l}$. for males between those with byssinosis grade 2 and those without byssinosis. The mean length of exposure was 22 years so that the difference in FEV levels could have been achieved by a trend in annual decline of $10 \mathrm{ml} /$ year. The survey was not designed to detect such a small difference since at the planning stage the evidence then available was of a larger difference in FEV between those with and without byssinosis. Since then evidence of a smaller difference of the same order as was found in this survey has been published by several workers (Lammers et al., 1964; Batawi et al., 1964; Mekky et al., 1967). The difference in mean FEV between non-bronchitics and bronchitics of grades 2 and 3 (Table 7) is in the opposite direction to the difference in annual decline in FEV and consequently little weight may be attached to the latter difference. The absence of any appreciable relationship of annual decline with FEV/FVC\% is in contrast to the results of Fletcher et al. (1970) who found that annual decline was much higher in those subjects with a lower FEV/FVC\%.

Of the two man-made fibre mills, one (mill 13) gave a low mean annual decline but the other (mill 4) gave a value slightly above average (Table 3 ). Workers in both mills had previously been exposed to cotton; 10 out of 38 of those in the annual decline study from mill 4 had worked with cotton within five years of entering the survey, and for mill 13 the proportion was 41 out of 44 . Thus, if those in mill 13 had previously worked in a very dirty mill a possible explanation for their low mean decline might be that they were recovering from this experience. However, the mean standardized FEVs appear to make this unlikely. For mill 13 the means were $2 \cdot 24$ and $3 \cdot 15 \mathrm{l}$. for females and males respectively, for mill 4 , 2.20 and 3.021 ., and for the whole 'annual decline' population $2 \cdot 23$ and $3 \cdot 121$.

The card tenters, strippers and grinders, and drawframe tenters had higher mean annual declines than the speedframe tenters, and although the first three jobs were more dusty there was nevertheless no overall relationship between annual decline and dust level. This suggests that there is something other than the current dust levels expressed as mass concentration causing the difference between these jobs. Most of the workers had been employed for more than 10 years and therefore they would have been exposed before the introduction of approved dust control guards on carding engines (Ministry of Labour 1957, $1960,1961)$. In this earlier period they would have been exposed to higher dust levels, particularly those working nearer the carding engines. A possible interpretation of our finding is therefore that the difference in annual decline between the above jobs is a residual effect from earlier conditions. However, if this interpretation is correct it is surprising that the mean standardized FEVs for all four jobs are within 0.051 . of the mean.

Cigarette smokers had a mean annual decline $19 \mathrm{ml} /$ year more than non- and ex-smokers. This difference was significant and comparable with a mean difference of $15 \mathrm{ml} /$ year reported by Higgins et al. (1968) and of $18 \mathrm{ml} /$ year found by Fletcher et al. (1970).

The relationships between Monday fall in FEV and the different dust components for the non and grade $\frac{1}{2}$ byssinotics enable an examination to be made of the contribution of the different size grades of dust to the acute change in FEV, but the correlations between these different size grades lower the sensitivity of this examination. The component with the lowest correlation with Monday fall is fly $(\mathrm{r}=0.308)$ but after allowing for fly, the variability accounted for by the inclusion of fine dust is signi- 
ficant only at a low level $(P<0 \cdot 1)$. Thus the evidence that the dust particles less than $2 \mathrm{~mm}$ in length are contributing to the acute change is significant only at this level. From consideration of the sizes of the upper airways it is to be expected that the fine dust would cause the greatest effect and therefore that the relationships between Monday fall in FEV and the respirable or fine dust fractions would be the more generally applicable over conditions where the dust composition was markedly different from that pertaining in this survey. For the subjects contributing to these relationships the dust concentrations were such that $18 \%$ of the total dust was respirable and $42 \%$ was fine.

In cotton mills there is an increased acute fall in FEV even in those not complaining of chest tightness on a Monday but the change is on average larger in those with byssinosis. Thus it can be conjectured that a high Monday fall in FEV indicates a susceptibility to develop byssinosis. Batawi et al. (1964) pointed out that the value of Monday fall would be enhanced if it could be used to detect those likely to develop byssinosis with permanent disability and that a prospective study was necessary to determine this point. The results of this study provide an answer to only half their question since because of the lack of accuracy of the annual decline in FEV it was not possible to deduce whether workers with a high Monday fall are at risk of developing chronic changes in their respiratory ability. However, it was demonstrated that those workers who apparently developed byssinosis during the survey had the higher values of Monday fall in FEV.

We are greatly indebted to the managements, workers, and welfare staffs of all the mills. Without their cooperation the survey could not have been made. The British Spinners' and Doublers' Association, the United Textile Factory Workers' Association, and the National Union of Textile and Allied Workers also gave us valuable support.

Dr. J. C. Gilson and Professor R. S. F. Schilling were involved in the planning of the survey and we are grateful for their advice and encouragement throughout. We are indebted to Dr. P. J. Nicholls who measured the bioactivities of the dusts and to Mr. A. W. Hyett who designed and made the dust sampling equipment.

We also wish to thank Professors R. E. Lane and T. S. Scott of the Department of Occupational Health of Manchester University for their help; Dr. T. A. Lloyd Davies, now Chief Medical Adviser, Department of Employment for his support; the Medical Research Council for a grant to M.K.B.M.; and finally the technicians and other helpers who were involved in the day to day operation of the survey.

\section{References}

Batawi, M. A. El., Schilling, R. S. F., Valić, F., and Walford, J. (1964). Byssinosis in the Egyptian cotton industry: changes in ventilatory capacity during the day. Brit. $J$. industr. Med., 21, 13-19.

Fletcher, C. M., Peto, R., Speizer, F. S., and Tinker, C. M. (1970). A follow-up study of the natural history of obstructive bronchitis. In: Bronchitis III: Proc. Third int. Symp. Bronchitis, Groningen, 1969, edited by N. G. M. Orie and R. van der Lende, pp. 103-116. Royal VanGorcum, Assen, The Netherlands.

Higgins, I. T.T., Gilson, J. C., Ferris, B. G. Jr., Waters, W. E., Campbell, H., and Higgins, M. W. (1968). Environmental epidemiology. IV. Chronic respiratory disease in an industrial town: a nine-year follow-up study. Preliminary report. Amer. J. publ. Hlth, 58, 1667-1676.

—, and Oldham, P. D. (1962). Ventilatory capacity in miners-a five-year follow-up study. Brit. J. industr. Med., 19, 65-76.

Lammers, B., Schilling, R. S. F., and Walford, J. (1964). A study of byssinosis, chronic respiratory symptoms, and ventilatory capacity in English and Dutch cotton workers, with special reference to atmospheric pollution. Brit. $J$. industr. Med., 21, 124-134.

Lawther, P. J., Brooks, A. G. F., and Waller, R. E. (1970). Respiratory function measurements in a cohort of medical students. Thorax, 25, 172-177.

McKerrow, C. B. (1960). The use of pulmonary function tests in epidemiological work. In: Industrial Pulmonary Diseases, edited by E. J. King and C. M. Fletcher, pp. 127-138. Symposium held at Postgraduate Medical School of London, Sept. 1957 and March 1958. Churchill, London.

, McDermott, M., and Gilson, J. C. (1960). A spirometer for measuring the forced expiratory volume with a simple calibrating device. Lancet, 1, 149-151.

- and Rossiter, C. E. (1968). An annual cycle in the ventilatory capacity of men with pneumoconiosis and of normal subjects. Thorax, 23, 340-349.

Medical Research Council (1960). Standardised questionaries on respiratory symptoms. Brit. med. J., 2, 1665.

- (1966). Chronic bronchitis and occupation. Brit. med. J., 1, 101-102.

Mekky, S., Roach, S. A., and Schilling, R. S. F. (1967). Byssinosis among winders in the cotton industry. Brit. J. industr. Med., 24, 123-132.

Ministry of Labour. Third (1957), Fourth (1960), and Final (1961). Dust in card rooms. Reports of the Joint Advisory Committee of the Cotton Industry. H.M.S.O., London.

Ministry of Technology. (1964, 1965, 1966, 1967). The Investigation of Air Pollution. National Survey Annual Summary: Table 1 for the year ended March 1964, 1965, 1966, 1967. Warren Spring Laboratory. H.M.S.O., London.

Molyneux, M. K. B., and Tombleson, J. B. L. (1970). An epidemiological study of respiratory symptoms in Lancashire mills, 1963-66. Brit. J. industr. Med., 27, 225-234.

Roach, S. A., and Schilling, R. S. F. (1960). A clinical and environmental study of byssinosis in the Lancashire cotton industry. Brit. J. industr. Med., 17, 1-9.

Schilling, R. S. F. (1956). Byssinosis in cotton and other textile workers. Lancet, 2, 261-265.

-, Hughes, J. P. W., Dingwall-Fordyce, I., and Gilson, J. C. (1955). An epidemiological study of byssinosis among Lancashire cotton workers. Brit. J. industr. Med., 12, 217-227.

Yates, F. (1934). The analysis of multiple classifications with unequal numbers in the different classes. J. Amer. statist. Ass., 29, 51-66.

Received for publication February 10, 1972. 